\title{
Bioprospecting of Fungi for Melanin fabrication: A Comprehensive Review
}

\author{
Avinash Irappa Ammanagi ${ }^{1}$, Abhijeeth Shivappa Badiger ${ }^{2}$, Shivasharana C. T. ${ }^{*}$ \\ ${ }^{1}$ Department of Studies in Biotechnology and Microbiology, Karnatak University Dharwad, Karnataka, India. 580003 \\ ${ }^{2}$ Sri Dharmasthala Manjunatheshwara College, Department of Biotechnology, Ujire, India. 574240 \\ *Corresponding Author: shivaskud@gmail.com, Tel.: +919482081120
}

Available online at: www.isroset.org

Received: 10/Aug/2019, Accepted: 24/Aug/2019, Online: 31/Aug/2019

\begin{abstract}
Melanin is a gloomy diffusive shade, present as a self-protective operator in miscellaneous life forms including microorganisms, plants, animals and human beings. Melanin assumes numerous self-defensive parts, for example, hindering of UV radiation, free radical adsorption, and lethal iron chelation, penetrating of phenolic mixes and defending against ecological pressure. Therefore, it is a conventional compound in remedy, pharmacology and beauty care products. Melanin is arranged from L-tyrosine by means of a development of enzymatic and non-enzymatic reactions by the chemical tyrosinase (EC 1.14.18.1). To begin with, tyrosinase catalyzes the hydroxylation of L-tyrosine to L-dihydroxyphenylalanine (L-DOPA). The L-DOPA is reacted to dopachrome, which is changed over to melanin by a progression of non-enzymatic oxido-reduction reactions. Chemical production of melanin is cost effective so microbial production of melanin is considered to be good in industrial scale. Melanin is critical component of some the microorganisms as reported. This review is concerned with transformed classes of melanin, pathway of melanin; factors influence the melanin production and application of melanin isolated from different fungi.
\end{abstract}

Keywords-Melanin, Tyrosine, Tyrosinase, L-DOPA, Fungi.

\section{INTRODUCTION}

The name "melanin" originates from the old Greek melanos, signifying "dull" and, as indicated by Borovansky (2011), the term was likely first connected by the Swedish scientific expert Berzelius in 1840 to call an indistinct dark removed from eye layers [2]. Be that as it may, first references of human skin pigmentation and by one means or another to the presence of melanin without utilizing the present name are exceptionally old. Pharaonic medication in the Ebers Papyrus $(1550 \mathrm{BC})$ represented a few diseases influencing skin shading [3], and one of them was most likely vitiligo, in spite of the fact that that term seemed considerable later, got from the Latin word "vitellus" signifying "veal" or pale pink skin $[4,5]$. The main moderately point by point composed interpretation on skin pigmentation in humankind originated from Herodotus in Greece, who depicted the darker skin of Persians, Ethiopians, and Indians in connection with Greeks.

Melanin is a gloomy diffusive shade, present as a selfprotective operator in miscellaneous life forms including microorganisms, plants, animals and human beings $[6,7,8$, 9, 10, and 11]. Melanin assumes numerous self-defensive parts, for example, hindering of UV radiation, free radical adsorption, lethal iron chelation, searching of phenolic mixes and protecting against ecological pressure. Therefore, it is a mainstream compound in remedy, pharmacology and beauty care products $[6,9,5]$. Melanin is prepared from L-tyrosine by means of a development of enzymatic and non-enzymatic reactions by the chemical tyrosinase (EC 1.14.18.1) [12]. To begin with, tyrosinase catalyzes the hydroxylation of Ltyrosine to L-dihydroxyphenylalanine (L-DOPA). The LDOPA is oxidized to dopachrome, which is changed over to melanin by an advancement of non-enzymatic oxidoreduction reactions [13, 14]. Right now, business melanin is set up from sepia extract or by engineered implies, for example, combining dopachrome with a suitable catalyst or gloomy with 5, 6-dihydroxyindole-2-carboxylic acid (either alone, with 5, 6-dihydroxyindole or with 3-amino-tyrosine). As of late, melanin creation by microorganisms has pulled in consideration as an earth concerned and economic other option to compound generation [15, 16, 7, 17, and 9].

\section{CHEMICAL NATURE OF MELANIN}

Melanin is polyphenolic polymer with an irregular structure that is created by the oxidation of polyphenolic phenols [18]. Melanin is insoluble gloomy darker color and considered as melanin without in regards to its science [19]. Melanin biosynthesis occurs by the procedure of melanogenesis 
which continues most normally with great Mason-Raper pathway [20, 21]. Prokaryotic and eukaryotic species contains mostly three kinds of melanin and eumelanin (dark or brown) (Figure 1), pheomelanin (yellow-red) (Figure 1) and allomelanin (darker) (figure 2). The critical assets of melanin are dim shading, insoluble in water and natural liquids, resistant to the solid acidic hydrolysis and susceptibility to degradation by solid oxidizing operators [22, 23]. They are comprised of stable free-radical occupants, which produce particular electron turn sound motions because of the nearness of unpaired electrons in the polymer [24]. Melanins have physicochemical properties that empower them to go about as sunny defenses, cation exchangers, medicate bearers, formless semiconductors, Xbeam and $\gamma$ beam protections and as commanding naturally dynamic operator $[25,26]$.

\section{CLASSES OF MELANIN}

Melanins are polymers of phenolic mixes. The broader grouping of such mixes, incorporating each one of them put together in Pro-and Eukaryota, contains three fundamental kinds of such polymers:

Eumelanins (dark or darker) - brought over the duration of oxidation of tyrosine (as well as phenylalanine) to odihydroxyphenylalanine (DOPA) and dopaquionone (Figure 1), which additionally experiences cyclization to 5, 6dihydroxyindole (DHI) or 5, 6-dihydroxyindole-2-carboxylic acid (DHICA) [27, 28, 29].

Pheomelanins (yellow-red) - which are at first joined basically like eumelanins, however DOPA experiences cysteinylation, specifically or by the media-tion of glutathione (Figure 1). The finished result of this response, cysteinyl DOPA, additionally polymerizes into different subsidiaries of benzothiazines [29, 30, and 31].

Allomelanins - the least considered and the most heterogenous gathering of polymers, which rise through oxidation/polymerization of di-(DHN) or tetrahydroxynaphthalene, by means of the pentaketide pathway driving through flavioline to different shaded polymers of DHN-melanins (Figure 2), homogentisic acid (pyomelanins) , $\gamma$-glutaminyl-4-hydroxybenzene, catechols, and of 4-hydroxyphenylacetic acid [29, 32, 33, 34, 35, 36]. As a rule, pheomelanins contain sulfur, though most kinds of allomelanins don't contain nitrogen. The second essential distinction concerns arrangement of quinone or quinonimine deposits in melanins: ortho-setup is available in eu-and pheomelanins, and para-(polymers of $\gamma$-glutaminyl-4hydroxybenzene) or meta-(polymers of DHN) in allomelanins [29].

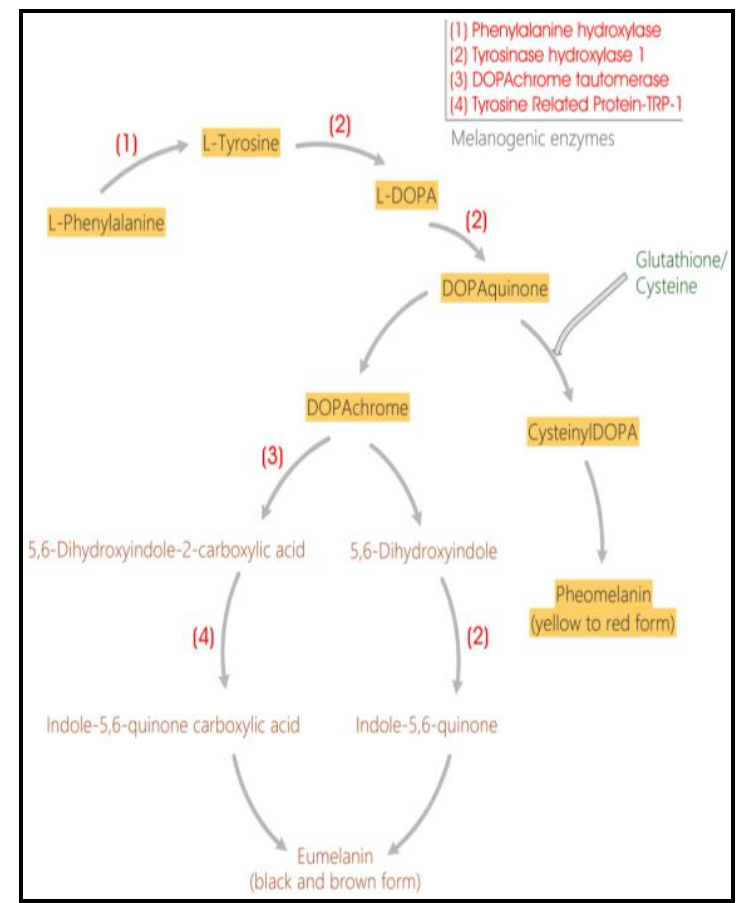

Figure 1. The Raper-Mason pathway depicting role of melanogenic enzymes in the synthesis of eumelanin and pheomelanin [modified from 18, 30, 31, and 29].

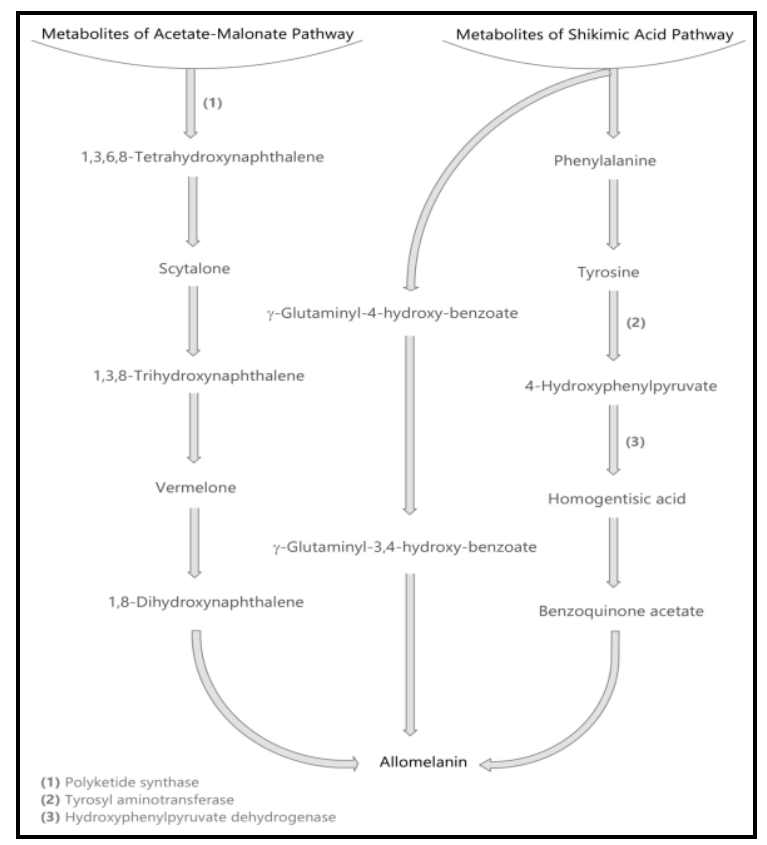

Figure 2. Biosynthetic pathway of fungal allomelanin from metabolites of acetate-malonate pathway and shikimate pathway [modified from 28, 29, 35, 41, and 47].

\section{PATHWAYS OF MELANIN PRODUCTION}

Various techniques, including electron paramagnetic resonance [24], X-ray diffraction [37], infrared, ultraviolet 
and visible spectroscopy [38], and nuclear magnetic resonance [39], have been used to elucidate the melanin structure from different organisms. These studies have shown that fungi can produce different types of melanins by oxidative polymerization of phenolic or indolic compounds $[18,28]$. Melanin in cell walls of Basidio mycotina is derived from phenolic precursors, as glutaminyl- 3, 4dihydroxybenzene (GDHB) or catechol. In the parasitic fungus Ustilago maydis, polymerization of catechol dimers with the formation of fibrils of melanin was shown [5, 40]. The precursor of melanin in Agaricus bisporus and other Basidiomycetes is a metabolite of the shikimic acid pathway$\gamma$-glutaminyl-4-hydroxybenzene oxidized under the action of peroxidase and/or phenolase into $\gamma$-glutaminyl-3,4benzoquinone, followed by its polymerization(Figure 2) [5, 41]. C. neoformans, a pathogenic basidiomycetous yeast, is known to synthesize DOPA-melanin when o-diphenolic compounds, such as 3, 4 dihydroxyphenylalanine, are present in the culture medium. This fungus may use a wide array of substrates, such as D- and L-dopamine [5, 42], homogentisic acid [43], catecholamines, and other phenolic compounds [44], maximizing its ability to produce melanin. Polymerization of exogenous substrates in this fungus occurs under the action of laccase [45]. However, it is important to emphasize that different properties are observed for melanins derived from different substrates. Comparison of the catecholamines L-dopa, methyldopa, epinephrine, and norepinephrine shows differences in term of color, yield, and thickness of the cell wall melanin layer. It was also observed that the pigments vary in the strength of the stable free radical signal detectable by EPR [5, 44]. In the Ascomycota fungi, melanin pigment is generally synthesized from the pentaketide pathway in which 1, 8-dihydroxynaphthalene (DHN) is the immediate precursor of the polymer, as described by Bell and Wheeler [5, 18], based on genetic and biochemical evidence obtained from Verticillium dahlia and $W$. dermatitidis ([7, 46]. A general model for fungal dihydroxynaphthalene (DHN)-melanin biosynthesis, in this pathway, the polyketide synthase (PKS) converts malonylCoA to $1,3,6,8$ tetrahydroxynaphthalene $(1,3,6,8$ - THN), which undergoes several reduction and dehydration reactions to produce scytalone, 1, 3, 8-trihydroxynaphthalene (THN), and vermelone. A further dehydration step leads to the intermediate 1, 8-dihydroxynaphthalene (DHN), which is polymerized to DHN-melanin, possibly by a laccase enzyme $[5,28,47]$. However, some species of this class, including Cladosporium resinae, Epicoccum nigrum, Hendersonula toruloidea, Eurotium echinulatum, Humicol agrisea, and Hypoxylon archeri, do not produce this type of pigment [5, $18,22,26,48]$.

The production of DOPA-melanin has also been investigated in other fungi such as Neurospora crassa [49], Podospora anserina [50], A. nidulans [51], A. oryzae, and $C$. neoformans [52]. A biosynthesis pathway for fungal DOPA- melanin, proposed by [18], is shown in Figure 1, which strongly resembles the pathway found in mammalian cells, though some of the details may differ. In this pathway, there are two possible starting molecules, L-DOPA and tyrosine. If L-DOPA is the precursor molecule, it is oxidized to dopaquinone by laccase. If tyrosine is the precursor, it is first converted to L-DOPA and then dopaquinone. The same enzyme, tyrosinase, carries out both steps. Dopaquinone, a highly reactive intermediate, forms leucodopachrome, which is then oxidized to dopachrome. Hydroxylation (and decarboxylation) yields dihydroxyindoles, which can polymerize spontaneously to form DOPA-melanin [5, 28, 47, and 53]. Some fungi have more than one biosynthetic pathway of melanins. For example, Aspergillus fumigatus synthesizes DHN-melanin [54] and also produces a second type of melanin, pheomelanins, from homogentisic acid by the tyrosine degradation pathway that protects the cell wall of hyphae from ROS, and gray-green DHN-melanins determine the structural integrity of the cell wall of conidia and their adhesive properties [55]. In Agaricus bisporus, melanins are formed from DOPA by tyrosinase and from $\gamma$ glutaminyl-4-hydroxybenzene by peroxidase and phenolase [56]. The extracellular fungal melanin, which is found in culture fluids usually in the form of granules, can be formed from some culture components, which are autoxidized or are oxidized by phenoloxidases released from the fungus during autolysis [18, 28, and 47].

\section{BIOLOGICAL FUNCTIONS OF MELANIN}

In spite of the distinction in their origination, melanin shades have various basic qualities that enable them to satisfy their defensive capacity. A few organic elements of melanins are nearly related to their creation arrangement and structure [5]. Melanins are nearly related to their concoction creation and structure. The nearness of unpaired electrons in the melanin structure is in charge of different properties, including cancer prevention agent, semiconductor, optical, electronic, and radio-and photoprotective [5, 45]. The impact of melanin improving the survival of microorganisms under antagonistic conditions is primarily because of its capacity as an extracellular redox support, which can kill oxidants produced by the microorganisms in light of natural pressure [45]. It has been accounted for that melanin contributes for harmfulness of $C$. neoformans, securing the pathogen against free radicals created immunologically [5, 57]. In $W$. dermatitidis and $A$. alternata, melanin presents protection from oxidants permanganate and hypochlorite, speaking to a key part in pathogenesis of diseases caused by these parasites $[5,58]$. Studies have demonstrated that melanin of zoopathogenic and a phytopathogenic organism is fundamental for their parasitizing, because of its cell reinforcement properties [5, 45]. Melanin shade removed from a few microbial animal types have demonstrated the capacity to reach free radicals (responsive nitrogen and oxygen species), turning into a 
potential characteristic cancer prevention agent. Melanin delivered by Schizophyllum collective indicated high free radical rummaging action in a dosage subordinate way, when the melanin fixation was expanded from 10 to $50 \mu \mathrm{g}$, the searching movement was likewise expanded from $87 \%$ to $96 \%$, like those got utilizing ascorbic acid (standard compound used to quantify free radical rummaging action) $[5,60]$.

Melanin color of Fonsecaea pedrosoi has cell reinforcement potential by lessening $\mathrm{Fe}(\mathrm{III})$ to $\mathrm{Fe}(\mathrm{II})$, guaranteeing the adjust of its redox concoction microenvironment and limiting the impact of oxidation of basic structures on parasitic development [5, 61]. The chelating energy of parasitic melanin can be clarified by different practical gatherings introduce in the structure of this color, which give a variety of numerous nonequivalent restricting destinations for metal particles [62, 63]. It has been accounted for that substances going about as cancer prevention agents shield cells from ROS-interceded DNA harm, which can bring about change and consequent carcinogenesis. The abundance free radicals may attack cell constituents, as the cell layer, nucleic acid, protein, catalysts, and different biomolecules, by peroxidation, bringing about the extreme harm of cell capacities and consequent genuine injurious consequences for the living being [64]. It has been accounted for that melanin shields melanocytes and keratinocytes from the enlistment of DNA strand broken by hydrogen peroxide, showing that this color likewise has an imperative cancer prevention agent part in the skin [5, 65]. Concentrates in our research facility demonstrated that melanin removed from hyper color profitable mutant (MEL1) of A. nidulans can reach the natural oxidants, as $\mathrm{HOCl}$, and might be a promising material in restorative plans to ensure the skin against conceivable oxidative harm [66]. There is test prove that microbial melanin may likewise go about as a hostile to maturing drug, because of its activity in decreasing the age of free radicals, cleaning up the free radicals delivered in overabundance, and upgrading the exercises of cancer prevention agent catalysts. Studies have demonstrated that one of the significant reasons for maturing is the surplus free radicals delivered amid the oxidative digestion in the human body [5, 67]. It was exhibited that the melanin created by parasite Lachnum singerianum YM296 altogether restrained the arrangement of lipid peroxidation items and backed off the maturing procedure, lifting the levels of superoxide dismutase, glutathione peroxidase, and catalase and diminishing the level of malondialdehyde in mice liver and mind homogenate and serum, proposing that this shade could be utilized as another against maturing drug [5, 68]. Examines have likewise demonstrated that some microbial melanin displays immunomodulatory movement through the hindrance of professional fiery cytokine creation in $\mathrm{T}$ lymphocytes and monocytes, and fibroblasts and endothelial cells $[5,69,70,71]$. Amid an incendiary reaction, cells of the inborn and obtained invulnerable frameworks discharge an assortment of middle people, for example, nitric oxide (NO), tumor corruption factor- $\alpha$ (TNF- $\alpha)$, interleukins (IL), and the receptive nitrogen and oxygen species, which are embroiled in the pathogenesis of various fiery ailments $[5,72]$. Bocca et al. (2006) [73] detailed that treatment of macrophages enacted in vitro with melanin from the parasite $F$. pedrosoi repressed the creation of nitric oxide and Th1 cytokines. The examination performed by $[5,74]$ demonstrated that the statement of inducible nitric oxide synthase quality diminished and lower levels of cytokines, for example, IL-12 and TNF- $\alpha$, were watched when initiated macrophages were hatched with melanized cells of the Fonsecaea monophora parasite. A few examinations have recommended that contagious melanin displays hostile to radiation movement in vivo and in vitro and after that could be investigated as a possible radio protector [5, 75, and 76]. Since melanin has a steady free radical residents, it is felt that the radio protective properties of this shade result from a mix of physical protecting and extinguishing of cytotoxic free radicals produced by radiation $[5,75]$. Ye et al. (2014) [77] demonstrated that Lachnum extracellular melanin (LEM404) had solid against bright radiation action in light of the fact that the survival rates of Escherichia coli, Staphylococcus aureus and Saccharomyces cerevisiae under UV radiation were altogether expanded after in vitro expansion of LEM404. Contrasted and the control gatherings, the cancer prevention agent safeguard frameworks, for example, superoxide dismutase and glutathione peroxidase exercises, were enhanced fundamentally in mice of examination gatherings, and the receptive oxygen species recognized by malondialdehyde content were diminished altogether. These outcomes affirmed that microbial melanin could be utilized as segment of photo-protective creams for the most part for its free radical searching instead of its light retention properties. The likely instruments of radioprotection by melanin have all the earmarks of being tweaked in genius survival pathways, invulnerable framework, and anticipation of oxidative pressure. This investigation affirmed the conceivable utilization of melanin-covered nanoparticles for securing against radiotoxicity amid radio immunotherapy [5, 76]. Late examinations have exhibited that, notwithstanding the capacity of exchanging electrons emerging under the activity of radiation, melanin additionally has ionic conductivity because of its capacity to change any kind of radiation vitality into warm as well as utilize it for the support of redox forms in cells [78]. It was expected that melanin shades, taking an interest in redox responses, can see the vitality of radiation (UV, unmistakable light, and radiation) and change over it into valuable decreasing force for metabolic procedures. This theory is bolstered by the revelation of melanized microorganisms in soils tainted by radioactive nuclides and regions around the harmed Chernobyl atomic reactors, which survive high radiation levels as well as have upgraded development upon 
presentation [45, 75, 79, and 80]. Inferable from its semiconductor property, melanin turns into a promising material for natural bio-electronic gadgets like transistors, sensors, and batteries [5, 78]. Contagious melanins likewise show development inhibitory impact against different microorganisms. The extracellular melanin detached from S. cooperative demonstrated huge antibacterial movement against E. coli, Proteus sp., Klebsiella pneumonia and Pseudomonas fluorescens and antifungal movement against dermatophytic growths, Trichophyton simii and T. rubrum $[5,60]$. The A. auricular melanin showed inhibitory movement on biofilm development of the three bacterial strains, E. coli K-12, Pseudomonas aeruginosa $\mathrm{PAO} 1$ and $P$. fluorescens $\mathrm{P}-3$, and there was a relative lessening in biofilm biomass with the expansion in shade focus. Silver nanoparticles joined Yarrowiali polytica melanin displayed antimicrobial movement against the pathogen Salmonella paratyphi, and they were likewise successful at disturbing biofilms on polystyrene and glass surfaces [5, 81]. These nanoparticles showed superb antifungal properties toward an Aspergillus sp. disconnected from a divider surface, proposing the use of these nanoparticles as successful paint added substances.

\section{FACTORS INFLUENCING SYNTHESIS OF MELANIN PRODUCTION}

Microbial color generation is currently one of the developing fields of research because of its potential for different modern applications, as foodstuff, beautifiers, pharmaceutical, and material assembling forms. In any case, it is realized that for the accomplishment of microbial maturation forms, it is important to pick the right beneficial culture strain and to decide the suitable development conditions [5, 82, 83, and 84]. A perfect color delivering microorganism ought to be equipped for utilizing an extensive variety of $\mathrm{C}$ and $\mathrm{N}$ sources; must be tolerant to $\mathrm{pH}$, temperature, and minerals fixation; and must give sensible shades yield. The nontoxic and nonpathogenic natures, combined with simple partition from cell biomass, are additionally favored characteristics. The capability of utilizing microorganisms as color sources is because of their unprecedented metabolic flexibility since they can be developed over an extensive variety of temperatures (10$\left.50^{\circ} \mathrm{C}\right), \mathrm{pH}(2-11)$, saltiness $(0-34 \%)$, and water action (0.6-1) and under oligotrophic or supplement rich conditions. They can develop in various culture frameworks (submerged and strong), and maturation conventions have been built up for expansive scale modern procedures. Moreover, these living beings can be hereditarily changed to build profitability and nature of the created colors $[5,85,86]$. Keeping in mind the end goal to enhance execution and diminish the cost of colors created by microbial aging, it is fundamental to distinguish the dietary and physical variables that affect the cell development and metabolite biosynthesis [5, 87, 84, and 88].
A few investigations have demonstrated that the organization of the development medium, nature and grouping of carbon and nitrogen sources, minerals, vitamins, temperature, $\mathrm{pH}$, the nearness of 50 Melanin oxygen and air circulation, light, stress, and illumination, among others, influence the development and color generation in microorganisms and that the control of the way of life conditions can bring about upgraded shade creation [5, 89, 90, 91, 92, 93, 94 and 95]. Test confirmations demonstrate that the development temperature impacts the execution of the color creation process, yet this impact relies upon the kind of living being. Pseudomonas requires $35-36^{\circ} \mathrm{C}$ for its development and color creation, while in Monascus purpureus, most extreme shade generation was seen at $30^{\circ} \mathrm{C}$ with a decrease of the yield at $37^{\circ} \mathrm{C}$ [96]. Another investigation in Monascus sp. $\mathrm{J} 101$ announced that the yield of color at $25^{\circ} \mathrm{C}$ was ten times higher than at $30^{\circ} \mathrm{C}$, likely because of long growing (120 hours) and lower consistency of the soup at $25^{\circ} \mathrm{C}$ contrasted with $30^{\circ} \mathrm{C}$ [97]. Concentrates created in our research center, utilizing a melanin-overproducing mutant (MEL1) from Aspergillus nidulans parasite, demonstrated that the higher generation of shade happened at hatching temperature of $28^{\circ} \mathrm{C}$ contrasted with $37^{\circ} \mathrm{C}[5,98]$. Inquiries about help that the $\mathrm{pH}$ of the medium likewise influences the development of growths and kind of color delivered. In types of Monascus, the $\mathrm{pH}$ impacts the yield and nature of the delivered shade, with the most noteworthy red color discharge and creation at soluble $\mathrm{pH}$ [5, 99, and 100]. Concentrates on wood-occupying parasites demonstrate that $\mathrm{pH}$ of the substrate possibly assumes a critical part in contagious melanin development. Parasites Trametes versicolor and Xylaria polymorpha tried on wood substrates created most extreme pigmentation at the $\mathrm{pH}$ run 4.5-5.0, with the exception of Scytalidium cuboideum, which deliver greatest power of red color at $\mathrm{pH} 6$ and blue shade at $\mathrm{pH} 8$ $[5,101]$. Metabolically, the impacts of $\mathrm{pH}$ and temperature on microbial color generation is related with changes in protein movement, so the way of life conditions may control certain exercises, for example, cell development, creation of essential and auxiliary metabolites, maturation, and oxidation procedures of the phone [5, 102]. The impact of light on intra-and extracellular shade creation was examined in five color delivering organisms: M. purpureus, Isaria farinosa, Emericella nidulans, Fusarium verticillioides and Penicillium purpurogenum [103].

These creators inferred that the development in the aggregate nonattendance of light expanded biomass and generation of extracellular and intracellular shades in all organisms. The organisms developed under red light have no impact, and green or yellow light brought about declining impact in every one of the growths, in this manner proposing the presence of photoreceptors receptive to dim and light in every one of the parasites. In a comparable report, $[5,104]$ noticed that the creation of shade by Monascus species likewise was favored 
when the growth was developed oblivious. A few examinations report that the color union requires legitimate air circulation likely identified with the oxygen reliance of some enzymatic responses in charge of the creation of shade. In Monascus ruber, it was watched that the most abnormal amounts of shades creation were gotten at an air circulation rate of $0.05 \mathrm{~L} \mathrm{~min}^{-1}$, which had all the earmarks of being plainly adequate for giving the parasite oxygen and evacuating carbon dioxide [105]. In our investigations, it was noticed that no melanin color creation happens amid stationary development of hypermelanized mutant (MEL1) from A. nidulans, demonstrating that the development of this shade includes the oxidative polymerization of the forerunners [5, 98]. Carbon and nitrogen are essential for cell digestion, and these sources are identified with the arrangement of biomass, the sort created color, and the yield of the coveted substance. These supplements may direct the statement of qualities of intrigue and actuate vital metabolic pathways for the creation of shades [5, 106, 107, and 94]. When all is said in done, glucose, an amazing carbon hotspot for development, meddles with the arrangement of numerous optional metabolites, including shades. For instance, the shade generation by Penicillium sp. was assessed within the sight of 10 diverse carbon sources, and the most extreme mycelial development was acquired with fructose, though the greatest shade creation was gotten with solvent starch [108]. This outcome demonstrates that the expanded biomass does not really bring about expanded color generation since shades created by parasites are auxiliary metabolites whose creation for the most part happens at the late development stage (idiophase) of these microorganisms [109]. The shade creation ability of contagious species having a place with the genera Penicillium, Aspergillus, Epicoccum, Lecanicillium and Fusarium was assessed in various culture media, and the outcomes demonstrated that the unpredictable media, as potato dextrose (PD) and malt remove (ME), favored expanded color generation [93, 5]. According to the creators, these media contain nutrients that can manage the declaration of qualities of intrigue and initiate metabolic pathways vital for the generation of shades. Studies have shown that the advancing or quelling impact of a nitrogen source on shade generation is strain subordinate. It has been accounted for those different sorts of peptone, utilized as a nitrogen source, can advance an expansion in the generation of shades in numerous microorganisms $[107,110,111,112]$. However a few microorganisms are supplemented with yeast extricate $(1 \%)$ and monosodium glutamate $(5 \%)$ as nitrogen source. In $M$. ruber, the utilization of glutamic corrosive as a nitrogen source demonstrated promising outcomes, either as invigorating the gathering of extracellular colors or adding to build the productivity of the shade creation process [94]. The creation of high measures of extracellular melanin by the organism Gliocephalo trichum simplex was gotten in societies supplemented with tyrosine $(2.5 \%)$ and peptone $(1 \%)[5,113]$. The improvement of medium arrangement is a vital procedure to expand color generation since a few wellsprings of carbon and nitrogen can be all the more effectively absorbed and advance higher yields of the coveted item. Amid the streamlining trials to improve the generation of melanin by Auricularia auricula, it was watched that dissolvable starch, tyrosine, peptone, $\mathrm{CaCO}_{3}$, and $\mathrm{K}_{2} \mathrm{HPO}_{4}$ had constructive outcomes, while glucose, $\left(\mathrm{NH}_{4}\right)_{2} \mathrm{SO}_{4}, \mathrm{MgSO}_{4}, \mathrm{CuSO}_{4}$, and $\mathrm{FeSO}_{4}$ adversely affected melanin creation [95]. In other investigation with $A$. auricula, it was watched that yeast concentrate, tyrosine, and lactose effects affect color generation and the advancement of medium brought about 2.14-overlay higher melanin focus than that of the un-optimized medium [5, 114]. Since the substrates for the generation of color firmly impact the cost of the bioprocess, there is a need to choose modest and effective substrates to make the procedure monetarily suitable on the modern scale. A lot of agro-mechanical buildups created from assorted monetary exercises have pulled in solid industry enthusiasm on the use of these deposits as economical substrates to help the development of microorganisms in bioprocesses. This procedure may speak to an additional incentive to the business and furthermore helps in taking care of contamination issues, decreasing or keeping their transfer in the earth [5, 116, 117, and 118].

Different investigations have announced the fruitful use of agro-mechanical buildups for the generation of contagious shades. The utilization of corn cob powder as a substrate for creation of colors by $M$. purpureus brought about more noteworthy color creation [119] than different substrates, as jackfruit seed [5, 120], corn soak alcohol, and grape squander [121]. Operating at profit yeast Hortaeawerneckii, it was watched that rice grain goes about as the least expensive hotspot for expanded creation of melanin by than wheat grain and coconut cake $[5,122]$. Wheat grain separate, L-tyrosine, and $\mathrm{CuSO}_{4}$ speak to the best blend of medium parts to get the greatest melanin yield from the growth $A$. auricula in submerged culture [5, 123].

\section{BIOTECHNOLOGICAL APPLICATIONS OF MELANIN}

\section{BIOELECTRONIC APPLICATIONS}

Lately, the gadgets business has been headed to create materials and segments that are less expensive and all the more naturally generous. As melanin has attributes of useful materials and bioorganic, a developing number of specialists in the fields of materials science and natural gadgets see the melanin with awesome enthusiasm, exploiting their properties for applications in natural electronic gadgets. Melanins exhibit fascinating optoelectronic properties, for example, high optical ingestion in the UV-Vis extend, great transmission electronic, and ionic conductivity obviously, pointing this biomaterial as a promising dynamic segment in natural electronic gadgets with low ecological effect $[5,124$, 
125, and 78]. Among the physical properties of melanin, the electrical conductivity is a standout amongst the most intriguing to examine in the viewpoint of mechanical application. The electrical conductivity properties of this biopolymer are like those of formless semiconductor solids, and after that it can be viewed as a natural semiconductor, which is to a great extent accessible and biocompatible and, therefore, less expensive and simpler to process as for inorganic semiconductors, as silicon germanium. Specifically, it can be viewed as a promising material for sensors and photovoltaic gadgets, because of broadband otherworldly absorbance and charge transport properties [5, 127]. The specialized writing depicts the joining of natural semiconducting polymers as melanin in silicon electronic gadgets in perspective of the likelihood of accomplishing multifunctional frameworks that consolidate electrical and optical properties of semiconductors, the auxiliary adaptability and mechanical qualities of materials, and handling polymeric $[5,126]$.

\section{ENVIRONMENTAL APPLICATIONS}

The chemical structure of melanin presents numerous oxygen-containing gatherings, including carboxyl, phenolic and alcoholic hydroxyl, carbonyl, and methoxy gatherings, which can tie to an expansive range of substances $[23,5]$. In writing, considers have affirmed that parasitic melanin goes about as metal chelators, improving the biomass-metal association and therefore its biosorption limit [5, 62]. Examine revealed that melanized organism Armillaria adsorb high convergences of cations from the encompassing condition; a few particles ( $\mathrm{Al}, \mathrm{Zn}, \mathrm{Fe}, \mathrm{Cu}$, and $\mathrm{Pb}$ ) were 50100 times more focused on rhizomorphs than in soil [128]. The outcomes acquired in our lab utilizing a melaninoverproducing mutant (MEL1) from A. nidulans parasite $[129,130,5]$ demonstrated that biosorption limit with respect to neodymium and lanthanum shifted with phase of development of this mutant; the biomass acquired following 72 hours of development showed a $75 \%$ expansion contrasted with the biomass of 48 hours. This outcome is identified with melanin generation amid development of the MEL1 mutant, since the biomass 48 hours is marginally pigmented, while the 72 hours biomass is dull because of the expanded creation of shade [131, 5]. Some melanized parasites have appeared to be great contender for bioremediation of defiled destinations, because of the capacity of contagious melanin to tie to overwhelming metals and radionuclides in polluted locales. Test confirm demonstrates that the collection of $90 \mathrm{Sr}$ by conidia or mycelium by a scope of microfungal animal varieties is more noteworthy in pigmented than in unpigmented species [132, 5]. Different investigations have shown the potential utilization of the melanized organisms for the expulsion of radionuclides and substantial metals from watery arrangements, giving an elective intends to influence cleanup of mechanical emanating $[5,133,134,135,75,80,136$, and
137]. As per the writers, these nanoshells have the potential use for natural bioremediation, for instance, to keep the spread of radioactive defilement to ground water in light of the fact that the melanin is required to epitomize the radioactive particles and in this way diminish their spread. Thus, melanin nanoshells might be utilized to contain radiation from radioactive waste and biomedical radioactive materials.

\section{MEDICAL APPLICATIONS}

Regardless of its high biocompatibility, the utilization of melanin as a novel biomaterial in pharmaceutical and biomedical applications detailed in writing is still rare. An investigation performed with melanin nanoparticles as biocompatible medication Nano carriers, utilizing metronidazole (anti-toxin tranquilize), demonstrated that melanin could be an exceptionally intriguing Nano carrier sedate discharge gadget since it emphatically reacts to $\mathrm{pH}$, being an extremely fascinating component for the treatment of digestive tract and colon illnesses, which would incredibly profit with $\mathrm{pH}$ focusing on $[138,5]$. Another examination demonstrated that fundamental melanin-shrouded nanoparticle $(\mathrm{MN})$ organization diminished hematologic lethality in mice treated with radiation and that these structures give effective insurance to bone marrow against radiotoxicity amid radio immunotherapy and sometimes outside pillar radiation treatment, allowing the organization to tumors of essentially higher measurements [5, 139]. Melanin has additionally been utilized to treat different kinds of dangerous growth tumors, issue of the safe framework including AIDS, sicknesses of blood cause and disarranges because of the aggravations in cell homeostasis, and complex and scarcely reparable mental issue (schizophrenia, epilepsy) including apprehensive and other administrative frameworks. An examination on the utilization of melanin for the treatment of Parkinson's ailment, an enhancement in the monkeys' general practical capacity and auxiliary engine signs by the organization of a successful measure of melanin in monkeys treated with MPTP (1-Methyl-4-phenyl-1,2,5,6tetrahydropyridine), a poison that causes a neurodegenerative sickness, was watched. This investigation exhibited that poison prompted Parkinson's illness could be anticipated in the melanin-treated creatures in light of the fact that the controlled melanin causes chelation or rummaging of poisons, for example, MPTP, along these lines keeping a neurodegenerative infection, for example, Parkinson's ailment. The consequences of this examination likewise demonstrated that melanin organization to help the recuperation of neurons in a warm blooded creature having neuron damage proposes that melanin can be utilized to treat Alzheimer's sickness [5, 140].

\section{CONCLUSION AND FUTURE PERSPECTIVES}


The capacity to create melanin is far reaching among microorganisms. From the compound perspective the main basic element of microorganism melanin is being a result of oxidative polymerization of different phenolic substances, in this manner melanin frame a very heterogenous gathering of biopolymers. As a result, melanogenesis can fill in for instance for transformative joining - the last item can be accomplished on different metabolic pathways, even in one taxon. As conversions in qualities deciding melanin generation are once in a while lethal, in any event under in vitro conditions, this component appears not to be key forever, in spite of the fact that it makes an effective adaptive favored standpoint. The possible situation of development may incorporate, initially, extracellular auto-oxidation of some phenolic mixes and amino acids because of the presence of oxygen in the climate, at that point, to enhance the natural conditions, dynamic emission of the substrates of melanogenesis and of chemicals supporting this procedure, trailed by a progressive adjustment to the intracellular control of the procedure, to fare or capacity of the item. In parallel "auxiliary" organic elements of melanin may have created. Other than mimicry, motioning, and additionally assurance against UV and unique light, free radicals, extraordinary temperatures, and keeping up a valid adjust of metal particles; there are three essential elements of melanin especially credited to microbial life forms: (1) The capacity of elective electron acceptors or transporters, making it possible to create vitality in forms analogical to oxidative phosphorylation, however under anaerobic conditions; (2) The capacity of a factor of destructiveness in pathogenic microorganisms bringing down the weakness to the resistance instruments of the hosts. Critical for both Pro-and Eukaryotic pathogens, it attracts one's consideration journey of particular focusing of individual microbial destructiveness factors as an elective antimicrobial procedure. As opposed to microorganisms, whose melanogenic compounds are typically emitted to the earth, on account of eukaryotic microbial catalysts melanin generation is generally associated with alteration of the receiver partition. The subatomic systems of misuse of melanin by parasitic organisms are refined and they should be a consequence of a long codevelopment. Therefore, these components are bad contender for the essential phenomena from which the implements of melanogenesis in higher Eukaryota advanced. As myxomycetes can both store melanins in the cell mass of the spores, and to deliver melanin in the plasmodium after introduction to light, they appear to be nearer to the primordial melanogenic Eukaryota. A nearer examination of protozoa will unquestionably uncover some new parts of creature melanogenesis, and, maybe, shed new light on the transformative inception of this wonder.

Melanin has physicochemical properties and natural exercises that make it a reasonable biomaterial for an extensive variety of uses in remedial, pharmaceutical, electronic, what's more, nourishment handling enterprises.
Moreover, this color has an impressive conspiracy biotechnological since it can be delivered on a substantial scale with ease, making its utilization for future down to earth applications financially favorable. In any case, it is important to grow the learning about the structure-propertywork connections for the advancement of melanin-based innovation. In the specific circumstance, we trust that the data in this review will be valuable and will support a more prominent number of investigates on contagious melanin, which may be valuable to convey inventive and supportable answers for human wellbeing what's more, nature.

\section{REFERENCES}

[1]. Borovansky J. History of melanosome research. In Melanins and melanosomes: biosynthesis, biogenesis, physiological, and pathological functions, Borovansky J, Riley PA (eds), WileyVCH Verlag GmbH \& Co., Weinheim, , pp. 1-19, 2011.

[2]. Berzelius JJ. Lehrbuch der Chemie. Arnoldische Buchbandlung, Leipzig, pp. 67-69, 1840.

[3]. Ebbell, B. The Papyrus Ebers: the Greatest Egyptian Medical Document. Levin and Munksgaard, Copenhagen, Denmark, pp. 1-135, 1937.

[4]. Westerhof W. The discovery of the human melanocyte. Pigment Cell Research, 19(3), 183-193, 2006.

[5]. Sandra RPS, Gabriela SS, Jazmina CRA, Helen FL, Rita CRG. Melanin. In Production of melanin pigment by fungi and its biotechnological applications, Miroslav B (ed), Intech Open, Rijeka, Croatia, pp. 47-97, 2017.

[6]. Ruan L, He W, He J, Sun M, Yu Z. Cloning and expression of mel gene from Bacillus thuringiensis in Escherichia coli. Antonie Van Leeuwenhoek, 87, 283-288, 2005.

[7]. Cabrera-Valladares N, Martinez A, Pinero S, Lagunas-Munoz VH, Tinoco R, de Anda R, Vazquez-Duhalt R, Bolivar F, Gosset G. Expression of the melA gene from Rhizobium etli CFN42 in Escherichia coli and characterization of the encoded tyrosinase. Enzyme Microb Technol, 38, 772-779, 2006.

[8]. Claus H, Decker H. Bacterial tyrosinases. Syst Appl Microbiol, 29, 3-14, 2006.

[9]. Wan X, Liu HM, Liao Y, Su Y, Geng J, Yang MY, Chen XD, Shen P. Isolation of a novel strain of Aeromonas media producing high levels of DOPA-melanin and assessment of the photoprotective role of the melanin in bioinsecticide applications. J Appl Microbiol 103, 2533-2541, 2007.

[10]. Yuan W, Burleigh SH, Dawson JO. Melanin biosynthesis by Frankia strain CeI5. Physiol Plant 131, 180- 190, 2007.

[11]. Shuster V, Fishman A. Isolation, cloning and characterization of a tyrosinase with improved activity in organic solvents from Bacillus megaterium. J Mol Microbiol Biotechnol, 17, 188-200, 2009.

[12]. Ikeda R, Sugita T, Jacobson ES, Shinoda T. Laccase and melanization in clinically important Cryptococcus species other than Cryptococcus neoformans. J Clin Microbiol, 40, 1214-1218, 2002.

[13]. Kohashi PY, Kumagai T, Matoba Y, Yamamoto A, Maruyama $\mathrm{M}$, Sugiyama M. An efficient method for the over expression and purification of active tyrosinase from Streptomyces castaneoglobisporus. Protein Expr Purif, 34, 202-207, 2004.

[14]. Marino SM, Fogal S, Bisaglia M, Moro S, Scartabelli G, De Gioia L, Spada A, Monzani E, Casella L, Mammi S, Bubacco L. Investigation of Streptomyces antibioticus tyrosinase reactivity toward chlorophenols. Arch Biochem Biophys, 505, 67-74, 2011. 
[15]. Fuqua WC, Coyne VE, Stein DC, Lin CM, Weiner RM. Characterization of melA: a gene encoding melanin biosynthesis from the marine bacterium Shewanella colwelliana. Gene, 109, 131-136, 1991.

[16]. Lopez-Serrano D, Solano F, Sanchez-Amat A. Identification of an operon involved in tyrosinase activity and melanin synthesis in Marinomonas mediterranea. Gene, 342, 179-187, 2004.

[17]. Selinheimo E, Saloheimo M, Ahola E, Westeholm-Parvinen A, Kalkkinen N, Buchert J, Kruus K. Production and characterization of a secreted, C-terminally processed tyrosinase from the filamentous fungus Trichoderma reesei. FEBS J, 273, 4322-4335, 2006.

[18]. Bell AA, Wheeler MH. Biosynthesis and functions of fungal melanins. Annual Review of Phytopathology, 24, 411-451, 1986.

[19]. Lewis FG, Antony MG. Melanin and novel melanin precursors from Aeromonas media. FEMS Microbiol Lett, 169, 261-268, 1998.

[20]. Raper HS. The anaerobic oxidases. Physiol Rev, 8, 245-282, 1928.

[21]. Mason HS. The chemistry of melanin: mechanism of the oxidation of dihydroxyphenyalanine by tyrosinase. J Biol Chem, 172, 83-99, 1948.

[22]. Nosanchuk JD, Casadevall A. Budding of melanized Cryptococcus neoformans in the presence or absence of $L$ DOPA. Microbiology, 149, 1945-1951, 2003a.

[23]. Riley PA. Melanin. Int J Biochem Cell Biol 29(11), 1235-1239, 1997.

[24]. Enochs WS, Nilges MJ, Swartz HM. A Standardized test for the identification and characterization of melanins using electron paramagnetic resonance (EPR) spectroscopy. Pigment Cell Res, 6, 91-99, 1993.

[25]. Della-Cioppa G, Garger SJ, Sverlow GG, Turpen TH, Grill LK. Melanin production E. coli from a cloned tyrosinase gene. Biotechnology (NY), 8(7), 634-638, 1990.

[26]. Saiz-Jimenez C. Microbial melanins in stone monuments. Sci Total Environ, 167(1), 273-286, 1995.

[27]. del Marmol V, Beermann F. Tyrosinase and related proteins in mammalian pigmentation. FEBS Lett, 381, 165-168, 1996.

[28]. Langfelder K, Streibel M, Jahn B, Haase G, Brakhage AA. Biosynthesis of fungal melanins and their importance for human pathogenic fungi. Fungal Gen Biol, 38, 143-158, 2003.

[29]. Plonka PM, Grabacka M. Melanin synthesis in microorganisms biotechnological and medical aspects. Acta Biochim Pol, 53(3), 429-443, 2006.

[30]. Kobayashi T, Vieira WD, Potterf B, Sakai C, Imokawa G, Hearing VJ. Modulation of melanogenic protein expression during the switch from eu- to pheomelanogenesis. J Cell Sci, 108, 2301-2309, 1995.

[31]. Nappi A, Ottaviani E. Cytotoxicity and cytotoxic molecules in invertebrates. Bio Essays, 22, 469-480, 2000.

[32]. Gibello A, Ferrer E, Sanz J, Martin M. Polymer production by Klebsiella pneumoniae 4-hydroxyphenylacetic acid hydroxylase genes cloned in Escherichia coli. Appl Environ Microbiol, 61, 4167-4171, 1995.

[33]. Kotob S, Coon SI, Quintero EJ, Weiner RM. Homogentisic acid is the primary precursor of melanin synthesis in Vibrio cholerae, a Hyphomonas strain and Shewanella colwelliana. Appl Environ Microbiol 61, 1620-1621, 1995.

[34]. Espin JC, Jolivet S, Wichers HJ. Kinetic study of the oxidation of $\gamma$-L-glutaminyl-4-hydroxybenzene catalyzed by mushroom (Agaricus bisporus) tyrosinase. J Agric Food Chem, 47, 34953502, 1999.

[35]. Funa N, Ohnishi Y, Fuji I, Shibuya M, Ebizuka Y, Horinouchi S. A new pathway for polyketide synthesis in microorganisms. Nature, 400, 897-899, 1999.
[36]. Jacobson ES. Pathogenic roles for fungal melanins. Clin Microbiol Rev, 13, 708-717, 2000.

[37]. Crippa R, Horak V, Prota G, Svoronos P, Wolfram L. Chemistry of melanins alkaloids. Chem Pharmacol, 36, 253-323, 1990.

[38]. Wilczok T, Bilińska B Buszman E, Kopera M. Spectroscopic studies of chemically modified synthetic melanins. Arch Biochem Biophys, 231(2), 257-262, 1984.

[39]. Duff GA, Roberts JE, Foster N. Analysis of the structure of synthetic and natural melanins by solid-phase NMR. Biochemistry, 27(18), 7112-7116, 1988.

[40]. Piattelli M, Fattorusso E, Nicolaus RA, Magno S. The structure of melanins and melanogenesis - $V:$ ustilago melanin. Tetrahedron, 21(11), 3229-3236, 1965.

[41]. Stüssi H, Rast DM. The biosynthesis and possible function of $\gamma$ glutaminyl-4-hydroxybenzene in Agaricus bisporus. Phytochemistry, 20(10), 2347-2352, 1981.

[42]. Eisenman HC, Mues M, Weber SE, Frases S, Chaskes S, Gerfen $\mathrm{G}$, Casadevall A. Cryptococcus neoformans laccase catalyses melanin synthesis from both D-and L-DOPA. Microbiology, 53(12), 3954-3962, 2007

[43]. Frases S, Salazar A, Dadachova E, Casadevall A. Cryptococcus neoformans can utilize the bacterial melanin precursor homogentisic acid for fungal melanogenesis. Appl Environ Microbiol, 73(2), 615-621, 2007.

[44]. Garcia-Rivera J, Eisenman HC, Nosanchuk JD, Aisen P, Zaragoza O, Moadel T, Dadachova E, Casadevall A. Comparative analysis of Cryptococcus neoformans acid-resistant particles generated from pigmented cells grown in different laccase substrates. Fungal Genet Biol, 42(12), 989-998, 2005.

[45]. Gessler NN, Egorova AS, Belozerskaya TA. Melanin pigments of fungi under extreme environmental conditions. Appl Biochem Microbiol, 50(2), 105-113, 2014.

[46]. Geis PA, Wheeler MH, Szaniszlo PJ. Pentaketide metabolites of melanin synthesis in the dematiaceous fungus Wangiella dermatitidis. Arch Microbiol 137, 324-328, 1984.

[47]. Butler MJ, Day AW. Fungal melanins: a review. Can J Microbiol, 44(12), 1115-1136, 1998.

[48]. Henson JM, Butler MJ, Day AW. The dark side of the mycelium: melanins of phytopathogenic fungi. Annu Rev Phytopathol, 37(1), 447-471, 1999.

[49]. Fling M, Horowitz NH, Heinemann SF. The isolation and properties of crystalline tyrosinase from Neurospora. J Biol Chem, 238(6), 2045-2053, 1963.

[50]. Esser K. Phenoloxidases in the ascomycete Podospora anserina. I. The identification of laccase and tyrosinase in the wild strain. Arch Mikrobiol, 46, 217-226, 1963.

[51]. Bull AT, Carter BLA. The isolation of tyrosinase from Aspergillus nidulans, its kinetic and molecular properties and some consideration of its activity in vivo. Microbiology, 75(1), 61-73, 1973.

[52]. Williamson PR, Wakamatsu K, Ito S. Melanin biosynthesis in Cryptococcus neoformans. J Bacteriol, 180(6), 1570-1572, 1998.

[53]. Prota G. Melanins and melanogenesis. Academic Press, San Diego, CA, 1992.

[54]. Tsai HF, Fujii I, Watanabe A, Wheeler MH, Chang YC, Yasuoka Y, Ebizuka Y, Kwon-Chung KJ. Pentaketide melanin biosynthesis in Aspergillus fumigatus requires chain-length shortening of a heptaketide precursor. J BiolChem, 276, 2929229298, 2001.

[55]. Schmaler-Ripcke J, Sugareva V, Gebhardt P, Winkler R, Kniemeyer O, Heinekamp T, Brakhage AA. Production of pyomelanin, a second type of melanin, via the tyrosine degradation pathway in Aspergillus fumigatus. Appl Environ Microbiol, 75(2), 493-503, 2009. 
[56]. Jolivet S, Arpin N, Wichers HJ, Pellon G. Agaricus bisporus browning: a review. Mycol Res 102(12), 1459-1483, 1998.

[57]. Wang G, Aazaz A, Peng Z, Shen P. Cloning and overexpression of a tyrosinase gene mel from Pseudomonas maltophila. FEMS Microbiol Lett, 185, 23-27, 2000.

[58]. Jacobson ES, Hove E, Emery HS. Antioxidant function of melanin in black fungi. Infect Immun 63(12), 4944-4945, 1995.

[59]. Gessler NN, Averyanov AA, Belozerskaya TA. Reactive oxygen species in regulation of fungal development. Biochemistry, 72(10), 1091-1109, 2007.

[60]. Arun G, Eyini M, Gunasekaran P. Characterization and biological activities of extracellular melanin produced by Schizophyllum commune (Fries). Indian J Exp Biol, 53(6), 380387, 2015.

[61]. Cunha MML, Franzen AJ, Seabra SH, Herbst MH, Vugman NV, Borba LP, Souza W, Rozental S. Melanin in Fonsecaea pedrosoi: a trap for oxidative radicals. BMC Microbiol 10(1), 19, 2010.

[62]. Fogarty RV, Tobin JM. Fungal melanins and their interaction with metals. Enzyme Microb Technol, 19(4), 311-317, 1996.

[63]. Nosanchuk JD, Stark RE, Casadevall A. Fungal melanin: what do we know about structure?. Front Microbiol, 6, 1-7, 2015.

[64]. Lopaczynski W, Zeisel SH. Antioxidants, programmed cell death, and cancer. Nutr Res, 21(1), 295-307, 2001.

[65]. Hoogduijn MJ, Cemeli E, Anderson D, Wood JM, Thody AJ. Melanin protects against Ho-induced DNA strand breaks through its ability to bind $\mathrm{Ca}$. Br J Dermatol 203, 148(4), 867.

[66]. Goncalves CRR, Pombeiro-Sponchiado SR. Antioxidant activity of the melanin pigment extracted from Aspergillus nidulans. Biol Pharm Bull, 28(6), 1129-1131, 2005.

[67]. Harman D. Free radical theory of aging: an update. Ann N Y Acad Sci, 1067(1), 10-21, 2006.

[68]. Lu Y, Ye M, Song S, Li L, Shaikh F, Li J. Isolation, purification, and anti-aging activity of melanin from Lachnums ingerianum. Appl Biochem Biotechnol, 174(2), 762-771, 2014.

[69]. Mohagheghpour N, Waleh N, Garger SJ, Dousman L, Grill LK, Tusé D. Synthetic melanin suppresses production of proinflammatory cytokines. Cell Immunol, 199(1), 25-36, 2000.

[70]. Mednick AJ, Nosanchuk JD, Casadevall A. Melanization of Cryptococcus neoformans affects lung inflammatory responses during cryptococcal infection. Infect Immun, 73(4), 2012-2019, 2005.

[71]. Plonka PM, Grabacka M. Melanin synthesis in microorganisms biotechnological and medical aspects. Acta Biochim Pol, 53(3), 429-443, 2006.

[72]. Cruvinel WDM, Mesquita Júnior D, Araújo JAP, Catelan TTT, Souza AWSD, Silva NPD, Andrade LEC. Immune system: Part I. Fundamentals of innate immunity with emphasis on molecular and cellular mechanisms of inflammatory response. Revistabrasileira de Reumatologia, 50(4), 434-447, 2010.

[73]. Bocca AL, Brito PP, Figueiredo F, Tosta CE. Inhibition of nitric oxide production by macrophages in chromoblastomycosis: a role for Fonsecaea pedrosoi melanin. Mycopathologia, 161(4), 195-203, 2006.

[74]. Zhang J, Wang L, Xi L, Huang H, Hu Y, Li X, Huang X, Lu S, Sun J. Melanin in a meristematic mutant of Fonsecaea monophora inhibits the production of nitric oxide and Th1 cytokines of murine macrophages. Mycopathologia, 175(5-6), 515-522, 2013.

[75]. Dadachova E, Bryan RA, Huang X, Moadel T, Schweitzer AD, Aisen $\mathrm{P}$, Nosanchuk JD, Casadevall A. Ionizing radiation changes the electronic properties of melanin and enhances the growth of melanized fungi. PLoS One, 2(5), 1-13, 2007.

[76]. Schweitzer AD, Howell RC, Jiang Z, Bryan RA, Gerfen G, Chen CC, Mah D, Cahill S, Casadevall A, Dadachova E. Physico- chemical evaluation of rationally designed melanins as novel nature-inspired radioprotectors. PLoS One, 4(9), 1-8, 2009.

[77]. Ye M, Guo G, Lu Y, Song S, Wang HY, Yang L. Purification, structure and anti-radiation activity of melanin from Lachnum YM404. Int J Biol Macromol, 63(1), 170-176, 2014.

[78]. Mostert AB, Powell BJ, Gentle IR, Meredith P. On the origin of electrical conductivity in the bio-electronic material melanin. Appl Phys Lett, 100(9), 093701, 2012.

[79]. Mironenko NV, Alekhina IA, Zhdanova NN, Bulat SA. Intraspecific variation in gamma-radiation resistance and genomic structure in the filamentous fungus Alternaria alternata: a case study of strains inhabiting Chernobyl reactor no. 4. Ecotoxicol Environ Saf, 45, 177-187, 2000.

[80]. Dighton J, Tugay T, Zhdanova N. Fungi and ionizing radiation from radionuclides. FEMS Microbiol Lett, 281(2), 109-120, 2008.

[81]. Apte M, Girme G, Bankar A, Ravikumar A, Zinjarde S. 3,4dihydroxy-L-phenylalanine derived melanin from Yarrowia lipolytica mediates the synthesis of silver and gold nanostructures. J Nanobiotechnol, 3-11, 2013.

[82]. Demain AL, Adrio JL. Strain improvement for production of pharmaceuticals and other microbial metabolites by fermentation. Nat Compd Drugs 1, 251-289, 2008.

[83]. Dufossé L, Fouillaud M, Caro Y, Mapari SAS, Sutthiwong N. Filamentous fungi are large scale producers of pigments and colorants for the food industry. Curr Opin Biotechnol, 26, 56-61, 2014.

[84]. Kumar A, Vishwakarma HS, Singh J, Kumar M. Microbial pigments: production and their applications in various industries. Int J Pharm Chem Biol Sci, 5(1), 203-212, 2015.

[85]. Babitha S. Microbial pigments. In Biotechnology for agroindustrial residues utilization: utilization of agro-residues, Nigam PSN, Pandey A (eds), Springer, Netherlands, pp. 147-162, 2009.

[86]. Meyer V, Wu B, Ram AFJ. Aspergillus as a multi-purpose cell factory: current status and perspectives. Biotechnol Lett, 33(3), 469-476, 2011.

[87]. Mapari SAS, Nielsen KF, Larsen TO, Frisvad JC, Meyer AS, Thrane U. Exploring fungal biodiversity for the production of water-soluble pigments as potential natural food colorants. Curr Opin Biotechnol, 16(2), 231-238, 2005.

[88]. Akilandeswari P, Pradeep BV. Exploration of industrially important pigments from soil fungi. Appl Microbiol Biotechnol, 100 (4), 1631-1643, 2016.

[89]. Dikshit R, Tallapragada P. Monascus purpureus: a potential source for natural pigment production. J Microbiol Biotechnol Res, 1(4), 164-174, 2011.

[90]. Marova I, Carnecka M, Halienova A, Certik M, Dvorakova T, Haronikova A. Use of several waste substrates for carotenoidrich yeast biomass production. J Environ Manage 95(S), 338342, 2012.

[91]. Sharmila G, Nidhi B, Muthukumaran C. Sequential statistical optimization of red pigment production by Monascus purpureus (MTCC 369) using potato powder. Ind Crops Prod, 44, 158-164, 2013.

[92]. Prajapati VS, Soni N, Trivedi UB, Patel KC. An enhancement of red pigment production by submerged culture of Monascus purpureus MTCC 410 employing statistical methodology. Biocatal Agric Biotechnol, 3(2), 140-145, 2014.

[93]. da Costa Souza PN, Grigoletto TLB, de Moraes LAB, Abreu LM, Guimarães LHS, Santos CR, Galvão LR, Cardoso PG. Production and chemical characterization of pigments in filamentous fungi. Microbiology, 162, 12-22, 2015. 
[94]. Hajjaj H, Goma G, François JM. Effect of the cultivation mode on red pigments production from Monascus ruber. Int J Food Sci Technol, 50(8), 1-6, 2015.

[95]. Zhang M, Xiao G, Thring RW, Chen W, Zhou H, Yang H. Production and characterization of melanin by submerged culture of culinary and medicinal fungi Auricularia auricula. Appl Biochem Biotechnol, 176(1), 253-266, 2015.

[96]. Joshi VK, Attri D, Baja A, Bhushan S. Microbial pigments. Indian J Biotechnol 2, 362-369, 2003.

[97]. Ahn J, Jung J, Hyung W, Haam S, Shin C. Enhancement of Monascus pigment production by the culture of Monascus sp. J101 at low temperature. Biotechnol Prog, 22(1), 338-340, 2006.

[98]. Lisboa HCF. Influence of culture conditions on the production of melanin pigment by Aspergillus fungus. Sao Paulo State University, Araraquara, Brazil, 2003.

[99]. Orozco SFB, Kilikian BV. Effect of $p H$ on citrinin and red pigments production by Monascus purpureus CCT3802. World J Microbiol Biotechnol, 24(2), 263-268, 2008.

[100]. Kang B, Zhang X, Wu Z, Wang Z, Park S. Production of citrininfree Monascus pigments by submerged culture at low $\mathrm{pH}$. Enzyme Microb Technol, 55, 50-57, 2014.

[101]. Tudor D, Robinson SC, Cooper PA. The influence of $p H$ on pigment formation by lignicolous fungi. Int Biodeterior Biodegrad, 80, 22-28, 2013.

[102]. Méndez A, Pérez C, Montañéz JC, Martínez G, Aguilar CN. Red pigment production by Penicillium purpurogenum $\mathrm{GH} 2$ is influenced by $\mathrm{pH}$ and temperature. J Zhejiang Univ Sci B, 12(12), 961-968, 2011.

[103]. Velmurugan P, Lee YH, Venil CK, Lakshmanaperumalsamy P, Chae JC, Oh BT. Effect of light on growth, intracellular and extracellular pigment production by five pigment producing filamentous fungi in synthetic medium. J Biosci Bioeng, 109(4), 346-350, 2010.

[104]. Zhou Z, Yin Z, Hu X. Corncob hydrolysate, an efficient substrate for Monascus pigment production through submerged fermentation. Biotechnol Appl Biochem, 61(6), 716-723, 2014.

[105]. Said FM, Chisti Y, Brooks J. The effects of forced aeration and initial moisture level on red pigment and biomass production by Monascus ruber in packed bed solid state fermentation. Int $\mathbf{J}$ Environ Sci Dev, 1(1), 1-4, 2010.

[106]. Ruiz B, Chávez A, Forero A, García-Huante Y, Romero A, Sánchez M, Rocha D, Sánchez B, Rodríguez-Sanoja R, Sánchez S, Langley E. Production of microbial secondary metabolites: regulation by the carbon source. Crit Rev Microbiol, 36(2), 146167, 2010.

[107]. Pradeep FS, Begam MS, Palaniswamy M, Pradeep BV. Influence of culture media on growth and pigment production by Fusarium moniliforme KUMBF1201 isolated from paddy field soil. World Appl Sci J, 22(1), 70-77, 2013.

[108]. Gunasekaran S, Poorniammal R. Optimization of fermentation conditions for red pigment production from Penicillium sp. under submerged cultivation. Afr J Biotechnol, 7(12), 1894-1898, 2008.

[109]. Nee Nigam PS. Production of bioactive secondary metabolites. In Biotechnology for agro-industrial residues utilization: utilization of agro-residues, Nigam PSN, Pandey A (eds), Springer, Netherlands, p. 129-145, 2009.

[110]. Tydelskaia IL, Rozhavin MA, Sologub VV. Pathogenicity factors of melanin-forming strains of Pseudomonas aeruginosa. Zh Mikrobiol Epidemiol Immunobiol 73-76, 1981.

[111]. Quereshi S, Pandey AK, Singh J. Optimization of fermentation conditions for red pigment production from Phomaher barum (FGCC\# 54) under submerged cultivation. J Phytol 2(9), 1-8, 2010.

[112]. Celestino JR, de Carvalho LE, da Paz Lima, M, Lima AM, Ogusku MM, de Souza JVB. Bioprospecting of amazon soil fungi with the potential for pigment production. Process Biochem, 49(4), 569-575, 2014.

[113]. Jalmi P, Bodke P, Wahidullah S, Raghukumar S. The fungus Gliocephalotrichum simplex as a source of abundant, extracellular melanin for biotechnological applications. World $\mathrm{J}$ Microbiol Biotechnol, 28(2), 505-512, 2012.

[114]. Sun S, Zhang X, Chen W, Zhang L, Zhu H. Production of natural edible melanin by Auricularia auricular and its physicochemical properties. Food Chem, 196, 486-492, 2016.

[115]. Sun S, Zhang X, Sun S, Zhang L, Shan S, Zhu H. Production of natural melanin by Auricularia auricula and study on its molecular structure. Food Chem, 190, 801-807, 2016.

[116]. Pandey A, Soccol CR, Mitchell D. New developments in solid state fermentation: I - bioprocesses and products. Process Biochem, 35(10), 1153-1169, 2000.

[117]. Singhania RR, Soccol CR, Pandey A. Application of tropical agro-industrial residues as substrate for solid-state fermentation processes. In: Current developments in solid-state fermentation, Pandey A, Soccol CR, Larroche C (eds), Springer, New York, pp. 412-442.

[118]. Lopes FC, Tichota DM, Pereira JQ, Segalin J, De Oliveira Rios A, Brandelli A. Pigment production by filamentous fungi on agro-industrial byproducts: an eco-friendly alternative. Appl Biochem Biotechnol, 171(3), 616-625, 2013.

[119]. Velmurugan P, Hur H, Balachandar V, Kamala-Kannan S, Lee KJ, Lee SM, Chae JC, Oh BT. Monascus pigment production by solid-state fermentation with corn cob substrate. J Biosci Bioeng, 112(6), 590-594, 2011.

[120]. Babitha S, Soccol CR, Pandey A. Jackfruit seed - a novel substrate for the production of Monascus pigments through solidstate fermentation. Food Technol Biotechnol, 44(4), 465-471, 2006.

[121]. Shivprasad S, Page W. Catechol formation and melanization by a $\mathrm{Na}^{+}$-dependent Azotobacter chroococcum: a protective mechanism for aeroadaption? Appl Environ Microbiol, 55, 1811$1817,1989$.

[122]. Rani MHS, Ramesh T, Subramanian J, Kalaiselvam M. Production and characterization of melanin pigment from halophilic black yeast Hortaea werneckii. Int J Pharma Res Rev, 2(8), 9-17, 2013.

[123]. Zou Y, Tian M. Fermentative production of melanin by Auricularia auricula. J Food Process Preserv, 41(3), e12909, https://doi.org/10.1111/jfpp.12909, 2017.

[124]. Goncalves PJ, Baffa O, Graeff CFO, Gonçalves PJ, Filho OB. Effects of hydrogen on the electronic properties of synthetic melanin. J Appl Phys 99(10), 104701, 2006.

[125]. Meredith P, Sarna T. The physical and chemical properties of eumelanin. Pigment Cell Res, 19(6), 572-594, 2006.

[126]. Ambrico M, Ambrico PF, Ligonzo T, Cardone A, Cicco SR, d'Ischia M, Farinola GM. From commercial tyrosine polymers to a tailored polydopamine platform: concepts, issues and challenges en route to melanin-based bioelectronics. J Mater Chem $C, 3(25)$, 6413-6423, 2015.

[127]. Ligonzo T, Ambrico M, Augelli V, Perna G, Schiavulli L, Tamma MA, Biagi PF, Minafra A, Capozzi V. Electrical and optical properties of natural and synthetic melanin biopolymer. $\mathrm{J}$ Non Cryst Solids, 355(22-23), 1221-1226, 2009.

[128]. Rizzo DM, Blanchette RA, Palmer MA. Biosorption of metal ions by Armillaria rhizomorphs. Can J Bot, 70(8), 1515-1520, 1992.

[129]. Goncalves CRR, Pombeiro-Sponchiado SR. Antioxidant activity of the melanin pigment extracted from Aspergillus nidulans. Biol Pharm Bull, 28(6), 1129-1131, 2005. 
[130]. Gonçalves RCR, Lisboa HCF, Pombeiro-Sponchiado SR. Characterization of melanin pigment produced by Aspergillus nidulans. World J Microbiol Biotechnol, 28(4), 1467-1474, 2012.

[131]. Caporalin CB. Comparison of biosorption of rare earth metals by melanized biomass of Aspergillus nidulans fungus in free and immobilized forms. Sao Paulo State University, Araraquara, Brazil, 2011.

[132]. Zhdanova NN, Vasilevskaya AI, Sadovnikov YS, Artyshkova LA. Dynamics of micromycete complexes from soils contaminated with radionuclides. Mikol i Fitopatol, 24(6), 504$512,1990$.

[133]. Singleton I, Tobin JM. Fungal interactions with metals and radionuclides for environmental bioremediation In Fungi and environmental change. Frankland JC, Magan N, Gadd GM (eds), Cambridge University Press, Cambridge, pp. 282-298, 1996.

[134]. Steiner M, Linkov I, Yoshida S. The role of fungi in the transfer and cycling of radionuclides in forest ecosystems. J Environ Radioact, 58(2), 217-241, 2002.

[135]. Zhdanova NN, Tugay T, Dighton J, Zheltonozhsky, V, Mcdermott P. Ionizing radiation attracts soil fungi. Mycol Res, 108(9), 1089-1096, 2004.

[136]. Dixit R, Wasiullah, Malaviya D, Pandiyan K, Singh UB, Sahu A, Shukla R, Singh BP, Rai JP, Sharma PK, Lade H, Paul D. Bioremediation of heavy metals from soil and aquatic environment: an overview of principles and criteria of fundamental processes. Sustain, 7(2), 2189-2212, 2015.

[137]. Shakya M, Sharma P, Meryem SS, Mahmood Q, Kumar A. Heavy metal removal from industrial wastewater using fungi: uptake mechanism and biochemical aspects. J Environ Eng, 142(9), C6015001, 2015.

[138]. Araújo M, Viveiros R, Correia TR, Correia IJ, Bonifácio VDB, Casimiro T, Aguiar-Ricardo A. Natural melanin: a potential $\mathrm{pH}$ responsive drug release device. Int J Pharm, 469(1), 140-145, 2014.

[139]. Schweitzer AD, Revskaya E, Chu P, Pazo V, Friedman M, Nosanchuk JD, Cahill S, Frases S, Casadevall A, Dadachova E. Melanin-covered nanoparticles for protection of bone marrow during radiation therapy of cancer. Int J Radiat Oncol Biol Phys, 78(5), 1494-1502, 2010.

[140]. Berliner DL, Erwin RL, McGee DR. Therapeutic uses of melanin. Patent No. 5776968, 1998.

\section{AUTHORS PROFILE}

Mr. Avinash Irappa Ammanagi obtained his M.Sc in 2015 from Karnatak University Dharwad and currently pursuing his Ph.D in Department of studies in Biotechnology and Microbiology, Karnatak University Dharwad under the guidance of Dr.

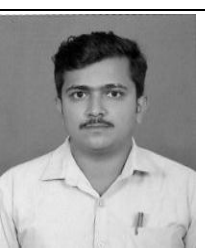

Shivasharana C.T. His main research work focuses on Ezymology, Microbial Biotechnology and Biotechnology.

Mr. Abhijeeth Shivappa Badiger obtained his M.Sc in 2015 from Karnatak University Dharwad and currently working as an Assistant professor in Department of Biotechnology Sri Dharmasthala Manjunatheswara College, Ujire. His main research work focuses on Medical

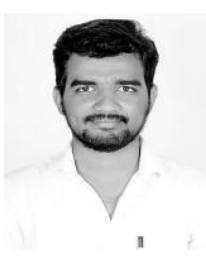
Biotechnology, Molecular Biology and Biotechnology.
Dr. Shivashrana C.T. obtained his M.Sc in 2000, M.Phil in 2001 and Ph.D in 2005 from Department of Biotechnology Gulberga University, Kalburgi. $\mathrm{He}$ is currently working as an Assistant professor in the Department Of Biotechnology and Microbiology, Environmental sustainable

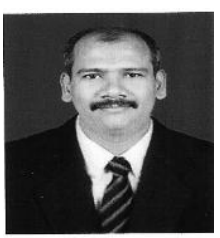
laboratory Karnatak University Dharwad. $\mathrm{He}$ has successfully guided $2 \mathrm{Ph}$.D student and presently 8 students are working under his guidance. He has 18 research paper and 4 Book chapters. He has attended more than 50 National and International Conference and workshops. His research areas are enzymology, algal Biotechnology and Environmental Biotechnology. 